\title{
Research Progress in Relation to Composite Brazing Materials with Flux
}

\author{
Bo Wang ${ }^{1,2}$, Weimin Long ${ }^{2,3, *}$, Mengfan Wang ${ }^{2}$, Pengzhi Yin ${ }^{2}$, Shaokang Guan ${ }^{1}$, Sujuan Zhong ${ }^{3}$ \\ and Songbai Xue ${ }^{4, *(1)}$
}

Citation: Wang, B.; Long, W.; Wang, M.; Yin, P.; Guan, S.; Zhong, S.; Xue, S. Research Progress in Relation to Composite Brazing Materials with Flux. Crystals 2021, 11, 1045. https:// doi.org/10.3390/cryst11091045

Academic Editor: Sergio Brutti

Received: 31 July 2021

Accepted: 26 August 2021

Published: 30 August 2021

Publisher's Note: MDPI stays neutra with regard to jurisdictional claims in published maps and institutional affiliations.

Copyright: (C) 2021 by the authors Licensee MDPI, Basel, Switzerland. This article is an open access article distributed under the terms and conditions of the Creative Commons Attribution (CC BY) license (https:// creativecommons.org/licenses/by/ $4.0 /)$.
1 Henan Key Laboratory of Advanced Magnesium Alloy, Zhengzhou University, Zhengzhou 450002, China; wangbo@camsouth.com.cn (B.W.); skguan@zzu.edu.cn (S.G.)

2 China Innovation Academy of Intelligent Equipment Co., Ltd., Ningbo 315700, China; 15173395631@163.com (M.W.); yinpengzhi93@163.com (P.Y.)

3 State Key Laboratory of Advanced Brazing Filler Metals and Technology, Zhengzhou Research Institute of Mechanical Engineering Co., Ltd., Zhengzhou 450001, China; zhongsj@zrime.com.cn

4 College of Materials Science and Technology, Nanjing University of Aeronautics and Astronautics, Nanjing 211106, China

* Correspondence: longweimin@camsouth.com.cn (W.L.); xuesb@nuaa.edu.cn (S.X.)

\begin{abstract}
Brazing was one of the earliest material-joining methods to be invented and widely used by humans. In the past 30 years, the technology and materials employed for brazing have developed rapidly and continuously. With the rise of the international new industrial revolution, the manufacturing industry is moving towards diversification, and brazing filler metals are also evolving in the direction of eco-friendliness, compounding and diversification. In the "carbon neutral" environment of 2021, green composite brazing materials will become mainstream. In this paper, the classification and characteristics of flux-containing brazing materials are summarized, and the preparation technology, composition design and typical application of composite brazing materials such as flux-cored brazing filler metal, flux-coated brazing filler metal and powder metallurgy brazing filler metal are analyzed. The article highlights the problems encountered in the research and development of composite brazing materials and proposes future development directions, such as with low-silver and cadmium-free brazing filler metals, the creation of new powder brazing filler metal-forming technology and improvements to the quality of brazing filler metals by shape control and performance optimization, to accelerate the process of brazing automation.
\end{abstract}

Keywords: flux-containing brazing filler metal; flux-cored; flux-coated; powder metallurgy

\section{Introduction}

Brazing is one of the fundamental technologies in manufacturing and is widely used in aerospace, rail transit, semiconductors, refrigerating appliances and other fields [1,2]. The traditional brazing process involves precoating the flux on the component to be brazed, removing the oxide film of the base metal and promoting the wettability of the filler metals during the brazing process [3]. The difficulties in this process include the inability to precisely control the flux, excessive residual flux and cleaning after brazing, which lead to serious wastage of flux and environmental pollution [4], as well as affecting the service life of weldments [5]. With the development trend of automatic and green brazing [6], these problems of filler alloy overflowing, poor joint quality and environmental pollution caused by excessive flux when using traditional filler alloy [7] and flux must be solved urgently.

The greening of brazing materials has become a long-term ambition worldwide. With increased environmental protection control, the halogens in brazing flux have become a major problem in respect of the continual involvement of brazing in green manufacturing. In particular, the fumes released by the decomposition of chloride and fluoride during brazing endanger the health of operators, the residues cause corrosion and decay of the 
surrounding materials and the wastewater after cleaning the brazing seam contains halides that cause environmental pollution. However, halogen elements play an important role in brazing materials. Reducing the use of halogen elements in the brazing process without increasing the cost or affecting the performance is an important subject in the field of brazing material research.

With the transformation and upgrading of the manufacturing industry related to brazing, the quantity of filler metals required for automated brazing is growing rapidly. However, currently, most of the commercial automatic brazing filler metals in China are occupied by foreign brands such as Umicore of Belgium and Lucas and Harris, both of the US, while the market share of Chinese brands is shrinking with the promotion of automated brazing [1]. The reason for the above phenomenon is that the manufacturing technology of filler metals made in China lags behind. These products have few varieties and poor performance, such as activity of flux and wettability of filler alloy. In addition, there are few atomistic theoretical and theoretical-leading-to-experimental realization works on novel technological brazing filler materials with prefabricated properties (such as the first-principles calculation method based on density functional theory [8]), which can bring about novel fundamental technologies nowadays [9-11]. Therefore, there is an urgent need to develop a novel filler alloy and flux composition, design a new filler metal structure and improve manufacturing technology [12].

Integrating the brazing filler metal with the brazing flux to achieve quantitative and fixed-ratio addition is the most promising means of achieving green and automated development of brazing materials. Flux-cored brazing filler metals (Figure 1a) use filler alloys to wrap the flux. Alternatively, coating the flux on the outer surface of the filler alloys is possible to create flux-coated brazing filler metals (Figure 1b). In a third approach, powder metallurgy brazing filler metal can be prepared by hot pressing of filler alloy particles and flux powder or powder forging followed by hot extrusion (Figure 1c). The development of these processes reflects the trend in progress in relation to brazing materials and technology [13], which aims to reduce the amount of flux and thus of pollution [14]. Flux-containing brazing materials have great application potential in refrigeration, power, tools, oil drill bits and the motor industry. In this article, we summarize different types of medium- and high-temperature composite and green filler metals considering three aspects: structure and preparation technology, composition design and typical applications.

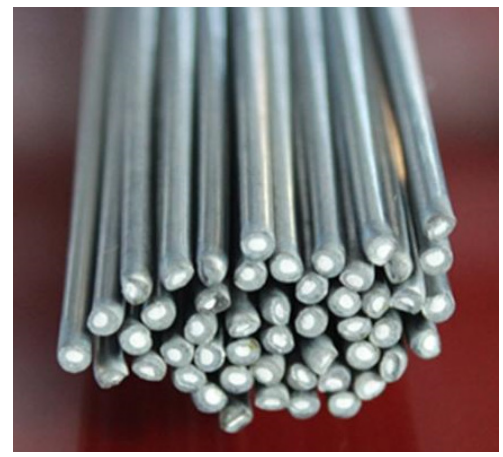

(a)

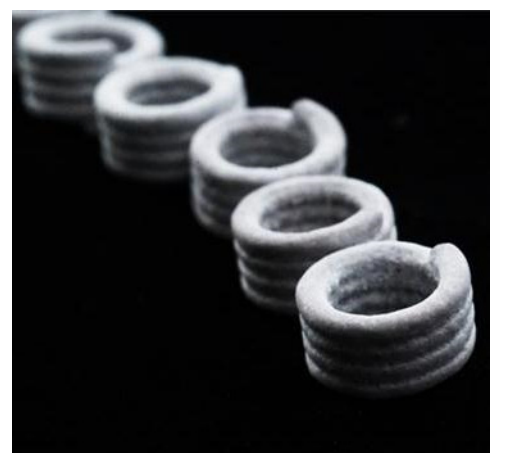

(b)

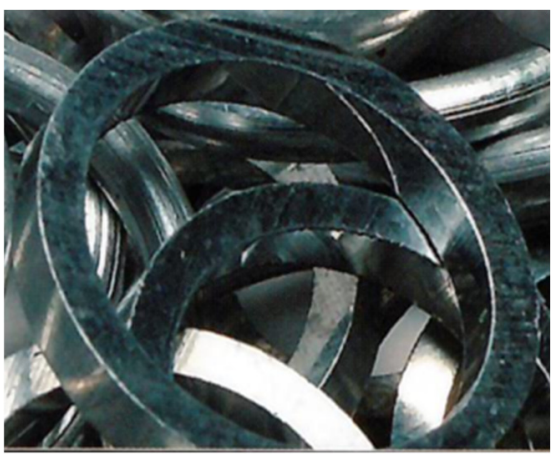

(c)

Figure 1. Flux-containing brazing materials: (a) flux-cored brazing filler metal; (b) flux-coated brazing filler metal; (c) powder metallurgy brazing filler metal.

\section{Research on Flux-Cored Brazing Filler Metals}

\subsection{Structure and Preparation of Flux-Cored Filler Metals}

The common structural forms of flux-cored filler metals are mainly seamless and seamed types [13]. Seamed flux-cored filler metal is divided into two types: butt seam (as shown in Figure 2a) and lap seam (as shown in Figure 2b [15] and Figure 2c). Seamless fluxcored filler metal has better moisture absorption resistance and lower powder leakage rates, 
while butt-seamed flux-cored filler metal absorbs the most moisture and causes serious powder leakage. Furthermore, considering flux splash during brazing, butt-seamed flux is better than lap-seam flux-cored filler metal, while seamless metal is prone to splash.

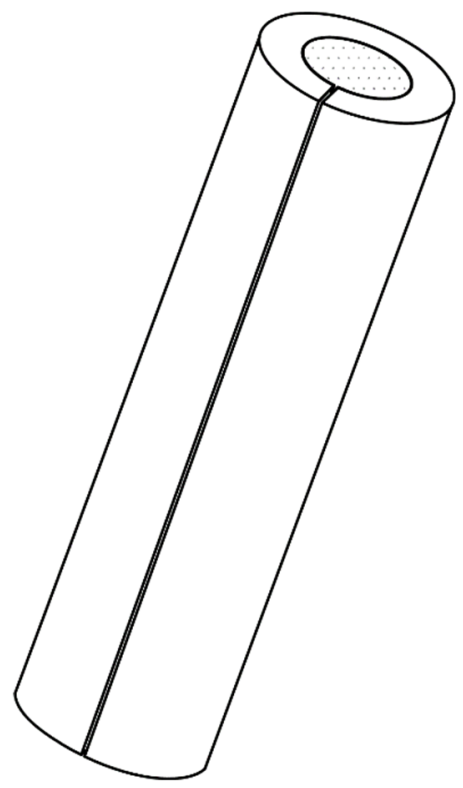

(a)

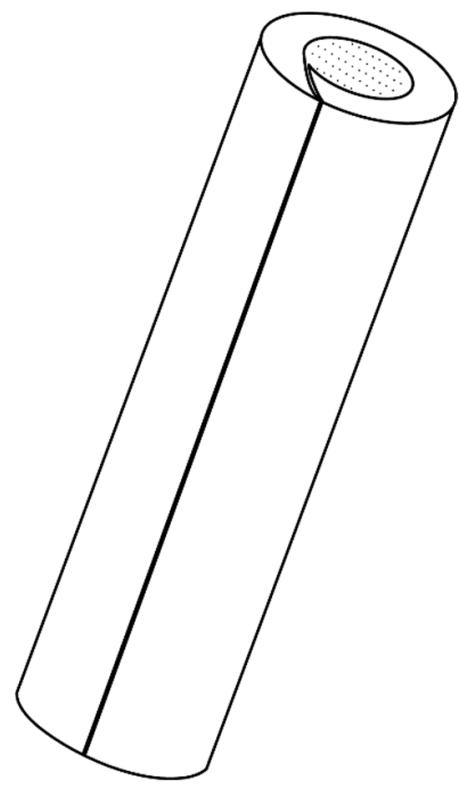

(b)

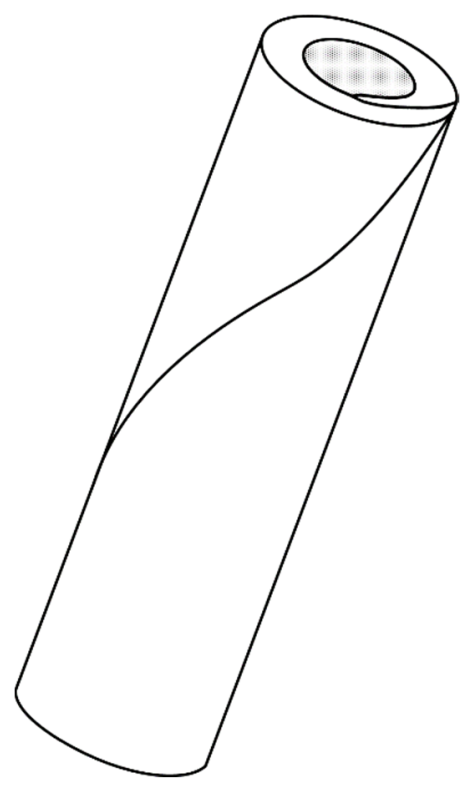

(c)

Figure 2. Schematic diagrams of seam types of flux-cored brazing materials [16]: (a) linear butt seam; (b) linear lap seam; (c) spiral lap seam.

The preparation technology for seamed flux-cored filler metal [17] mainly applies the cold-rolled metal strip method or the coil method. The cold-rolled metal strip method is commonly used worldwide and can be achieved by either tandem rolling or rollingdrawing. The tandem rolling method is relatively simple, with the processes of pay off, U-shaping, powder feeding, closing and rolling reduction all completed continuously on one production line. As this occurs, the material quality and installation accuracy of the rolls are strictly controlled. As for the rolling-drawing method (as shown in Figure 3), the diameter-reduction process is changed from rolling to drawing, and the processes are completed using different equipment (rolling mills, drawing machines). In recent years, with the emergence of new high-speed wire drawing machines and polymerized crystal diamond (PCD) drawing dies, the drawing process has become simple. The rollingdrawing method thus presents a promising opportunity to further improve the production efficiency and surface quality of flux-cored filler metal. Researchers from Zhengzhou Research Institute of Mechanical Engineering created flux-cored silver filler metal with a spiral seam structure (Figure 2c) [18], prepared via the strip rolling method [16]. The ribbon-shaped silver-based filler metal with internal surface roughening is rotated and rolled into a spiral tubular structure with lap joints. During the rolling process, brazing flux is added to the spiral tube, and then the diameter is reduced by drawing or rolling to prepare the flux-cored filler metal at a specified size. This technology can add flux efficiently and conveniently at a low cost. In addition, it is easy to achieve automatic production, which is fitting for the popularization and application of an automatic brazing process. Chen et al. $[19,20]$ successfully prepared brittle $\Phi 2.0 \mathrm{~mm}$ Al-10Si-10Cu flux-cored brazing wire using the rolling method. Shanghai Longshuo Welding Materials Co., Ltd. [21] used a cold-rolled composite strip ( 4045 aluminum alloy/ $\mathrm{Cu} / 4045$ aluminum alloy) to prepare a brazing filler metal, which solved the difficult problem of brittle flux-cored filler metal processing. The coiling method, however, was first developed by Lincoln Electric Co. (USA) for the production of flux-cored welding wire. This technology splits the cylindrical solid welding rod into two halves from the center. The coiling method has fewer cold-rolling 
passes and requires no intermediate annealing [17]. However, the coiling method is not suitable for the production of flux-cored filler metal with a fine diameter $(\leq 2.0 \mathrm{~mm})$ in terms of efficiency, cost or quality stability. As a result, this technology is rarely used to prepare flux-cored filler metals.

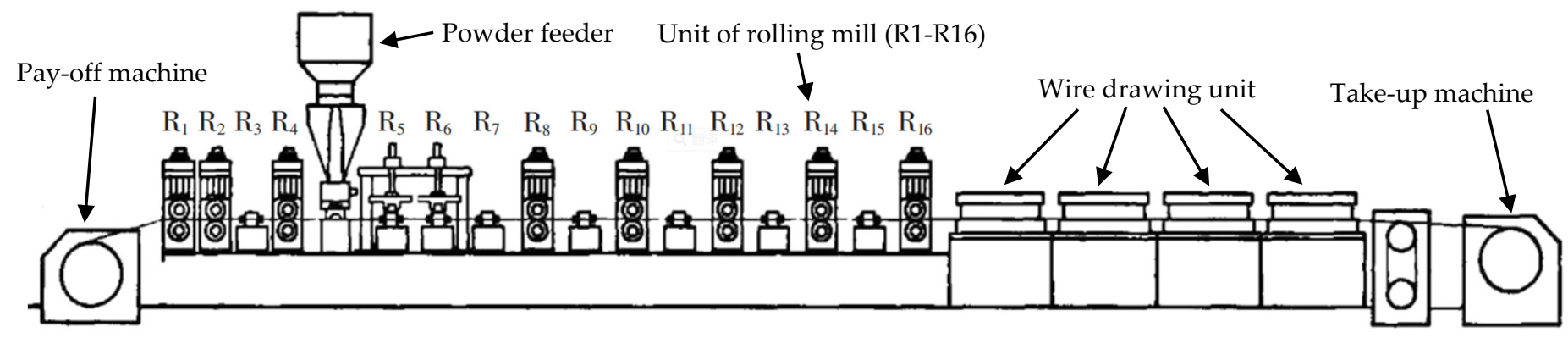

Figure 3. Processes of the rolling-drawing method for seamed flux-cored filler metal [16].

In comparison to seamed flux-cored filler metal, the manufacturing cost for seamless cored filler metal is relatively high. Its preparation technology mainly applies either the ingot extrusion method or the metal tube drawing method. Long [22] pioneered synchronous laminar extrusion preparation technology for seamless flux-cored aluminum filler metal in 2002. Through the integration of composite ingot casting, synchronous extrusion and roller mill drawing, a short process for the efficient preparation of seamless flux-cored aluminum filler metal was realized, which involved a positioning-temperaturetiming quantitative accurate response and efficient use of flux (Figure 4). The key difficulties of the process, however, were the pretreatment and compound addition of active flux. $\mathrm{Li}$ [23] used the ingot extrusion method to prepare a seamless silver-based flux-cored filler metal. First, the flux powder was filled into a tank and heated to a liquid state. Then, by feeding inert gas into the tank through the inlet valve, the liquid flux was pressed into a hollow filler alloy ingot, where it cooled and solidified. The metal tube drawing method is based on mechanical vibrations, which are utilized to fill a tube with mixed fluxcored powder. The tube is then sealed and rolled to prepare the brazing filler metal. The technology has low production efficiency and is prone to unstable powder filling, which contribute to its limited development. Shanghai Smick Welding Materials Co., Ltd. [24] prepared seamless flux-cored aluminum filler metals by the metal tube drawing method. The steps are as follows: extrusion and drawing to prepare a hollow aluminum alloy tube with an outer diameter of $12 \mathrm{~mm}$, filling the prepared seamless aluminum alloy tube with flux powder, sealing the two ends of the tube and then rolling, drawing and winding to obtain a seamless aluminum filler metal wire of $\Phi 2.4 \mathrm{~mm}$. Alternatively, the online welding method (using special welding machines-such as for high-frequency welding, laser welding or pulsed argon arc welding — to weld the seam) $[17,25,26]$ is a commonly used method for preparing seamless carbon steel and stainless steel flux-cored brazing wires. However, this involves a large welded pipe diameter and poor weldability to thinwalled nonferrous alloy filler metal, and the subsequent processing is difficult, so it has not been popularized and applied in flux-cored filler metal development.

\subsection{Composition and Application of Flux-Cored Filler Metals}

Flux-cored filler metal is mainly divided into flux-cored aluminum filler metal [27], flux-cored copper filler metal and flux-cored silver filler metal, according to the metal shell. Research in this area focuses on alloying or coating the outer filler alloy, the processes of which have been developed in recent years, and improving the properties and structure of the filler metal [28,29]. Using an in situ synthesis method [30-32] to prepare the coating on the surface of the outer filler alloy can solve the formation problem of brittle brazing filler metal. Preparation of an internal isolation metal layer (tin layer or indium layer), as shown in Figure 5, can protect the outer filler alloy from corrosion by the flux in the core and improve the wettability of the composite brazing filler metal. The thickness of the isolation 
metal layer is $0.001-0.08 \mathrm{~mm}$. The melting point of the tin layer is $232^{\circ} \mathrm{C}$, and the melting point of the indium layer is $156.6^{\circ} \mathrm{C}$. The flux in the core contains inorganic substances such as boric anhydride, potassium fluoride and potassium hydrofluoride, which are easy to absorb moisture and corrosive after moisture absorption. The insolation metal layer can inhibit flux from moisture absorption and then prevent outer filler alloy from flux corrosion. In addition, the insolation metal layer is preferentially melted into liquid during brazing, dissolves the flux and diffuses with the outer filler alloy, thus reducing the melting point of the composite brazing filler metal.

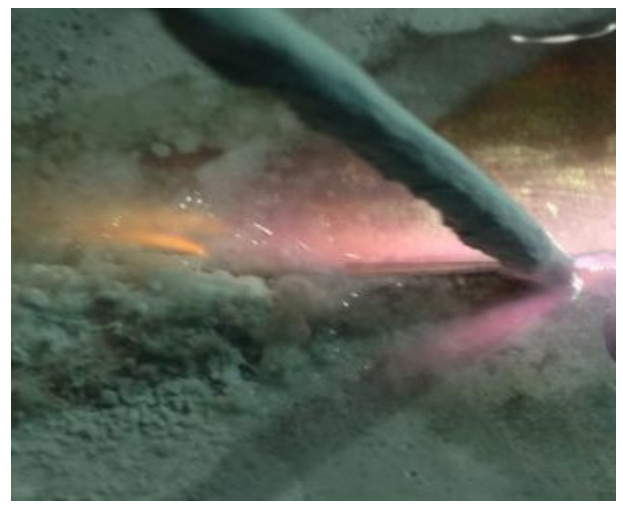

(a)

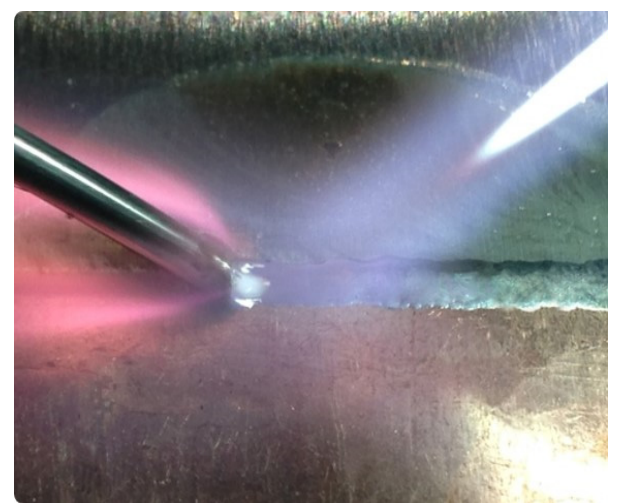

(b)

Figure 4. Comparison of traditional and flux-cored aluminum brazing filler metals [16]: (a) solid 4047 filler metal; (b) flux-cored $\mathrm{Zn}-15 \mathrm{Al}$ filler metal.

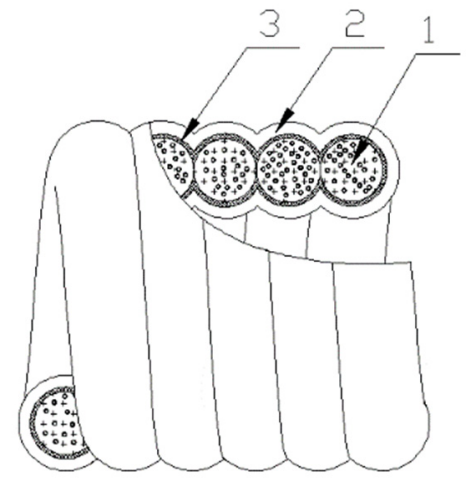

Figure 5. Schematic diagram of flux-cored brazing filler metal with internal isolation metal layer: 1 , flux in the core; 2 , outer filler alloy; 3 , internal isolation metal layer.

As shown in Figure 6, the core layer is added with particles (metal powder, alloy powder, oxide particles, etc.) to improve the brazing performance of the flux-cored brazing filler metal [33-40]. Synthetic growth of any composite materials is as dependent on the optimum addition of precursor/dopant [8,41]. Researchers at Harbin Institute of Technology [33] invented a self-fluxing flux-cored wire for aluminum/steel brazing. The core layer is mainly composed of Al-Si alloy powder, $\mathrm{Sn}, \mathrm{Ti}, \mathrm{Ni}, \mathrm{Zn}, \mathrm{Ag}$, rare-earth elements and fluoroaluminate. It is suitable for gas metal arc welding (GMAW) and gas tungsten arc welding (GTAW) and various heat source arcs in hybrid welding. Researchers at Nanjing University of Aeronautics and Astronautics separately studied the effect of $\mathrm{Ga}_{2} \mathrm{O}_{3}$ [40] and $\mathrm{CeO}_{2}$ [36] particles on the wettability of $\mathrm{Ag} 30 \mathrm{CuZnSn}$ flux-cored brazing filler metals. As presented in Figure 7, the results showed that $\mathrm{Ga}_{2} \mathrm{O}_{3}$ and $\mathrm{CeO}_{2}$ addition can improve wettability; the optimum addition was $0.4 \mathrm{wt} \%$ and $0.3 \mathrm{wt} \%$, respectively. Long [34] created a metal particle-reinforced flux-cored aluminum filler metal, which is prepared by mixing Al-Si, Cu-Si and Al-Cu master alloys and potassium fluoroaluminate. The brazing filler metal ensures the processing performance, improves the fluidity and wettability of the filler metal, reduces the ductile-brittle transition temperature and crack sensitivity 
and improves the low-temperature impact toughness and brazing strength of the weld. In addition, the author's recent research [42-44] shows that adding $\mathrm{Al}$ and Si powder to the core can aid deoxidation and film removal, reaction heat generation, purification and strengthening of the brazing joint due to the formation of a Al-Si bond at the atomistic level [45] during the brazing process. Adding Ga and B powder to the flux core can activate and enable the brazing metallurgical process, reduce the surface tension of the molten pool and improve the fluidity of the filler metal. Furthermore, adding a small amount of high-melting-point metal into the core can realize dispersion strengthening and inhibit segregation during the brazing filler metal solidification process, as well as improving the toughness, corrosion resistance and fatigue resistance of the brazing joint.

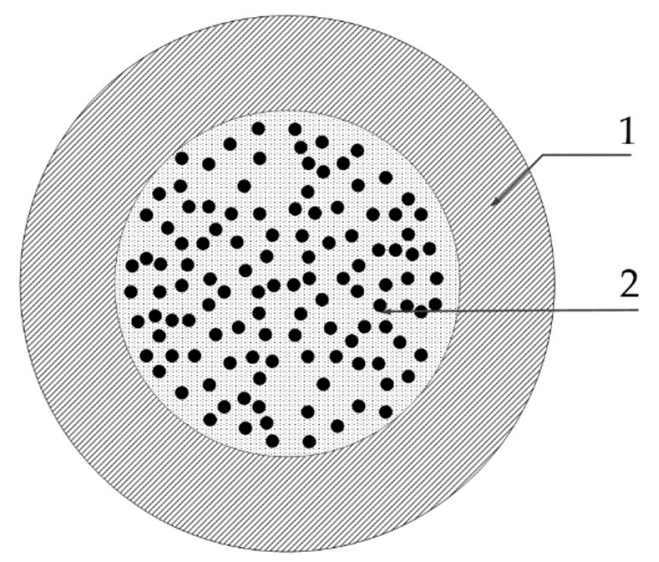

Figure 6. Schematic diagram of flux-cored brazing filler metal with particles [34]: 1, outer filler alloy; 2 , mixture of flux and active particles.

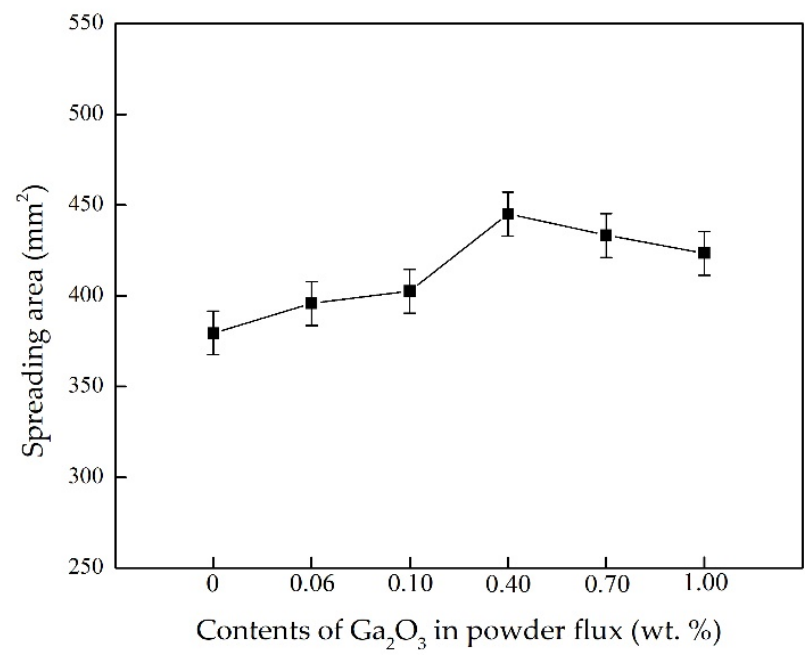

(a)

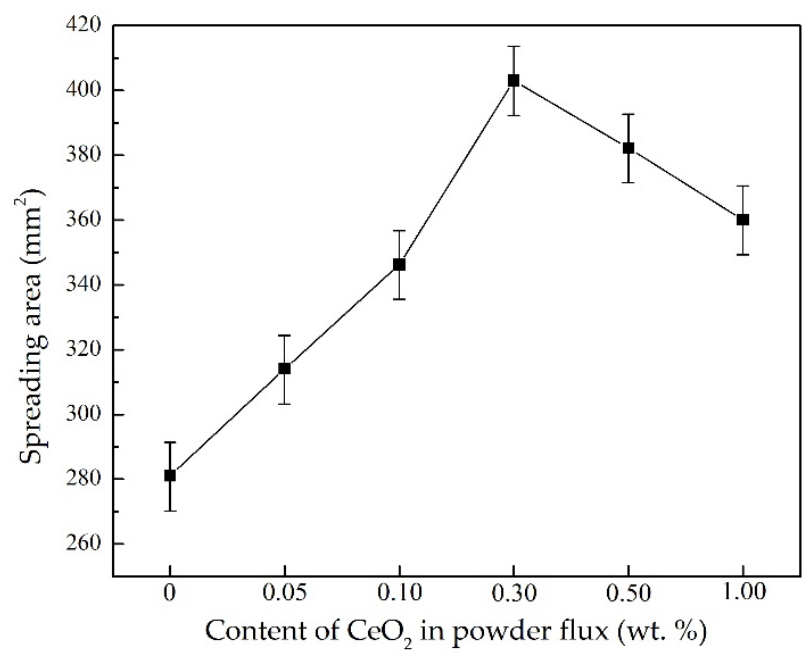

(b)

Figure 7. Effects of different oxides on the wettability of $\mathrm{AgCuZnSn}$ flux-cored brazing filler metal: (a) $\mathrm{Ga}_{2} \mathrm{O}_{3}$ [40]; (b) $\mathrm{CeO}_{2}[36]$.

\subsubsection{Flux-Cored Aluminum Filler Metal}

Aluminum brazing filler metal is mainly used for brazing $\mathrm{Al} / \mathrm{Al}$ or $\mathrm{Al} /$ dissimilar metal materials. Long first systematically explained the composition design, preparation and application of flux-cored aluminum filler metal in 2002, and then a large number of related papers and patents began to appear in the industry. At present, the commonly used flux-cored aluminum filler metals include $\mathrm{Al}-\mathrm{Si}$ and $\mathrm{Zn}-\mathrm{Al}$ series. Different alloying elements (such as $\mathrm{Cu}, \mathrm{Mn}, \mathrm{Zn}, \mathrm{Ag}$, Ni, etc.) can be added to Al-Si alloys [13]. Zhengzhou Research Institute of Mechanical Engineering [34] developed a metal particle-reinforced 
flux-cored aluminum brazing wire, which is composed of an Al-Si alloy shell filled with a core powder.

To research the application of flux-cored Al-Si filler metal, Zhou et al. [46] used Al-12Si flux-cored filler metal to join 5052-H32 aluminum alloy and H62-Y2 brass by arc weldingbrazing and then obtained a well-formed GTAW joint. Li et al. [47] used laser welding to braze a 6061-T6 aluminum alloy (2 mm) and DP590 steel with an Al-12Si flux-cored filler metal. The DP590 steel side had three bevel types: square, semi-Y and semi-V. Test results showed that the temperature gradient along the interface thickness direction of the joint with semi-V groove is the smallest, that the thickness of the intermetallic compound was unchanged and that the joint had the maximum tensile strength.

$\mathrm{Zn}-\mathrm{Al}$ filler metal is mainly used for flame brazing, resistance brazing and furnace brazing of $\mathrm{Cu} / \mathrm{Al}$ and steel/Al dissimilar metals in the refrigeration and electric power industries, and is especially suitable for nonoxygen acetylene flame brazing [27]. Zn-Al filler metal is mainly modified by adding Ag [48], Al [49], Si [50], Zr [51], rare-earth elements [52] or other elements [53]. To suppress the embrittlement of $\mathrm{Zn}-\mathrm{Al}$ filler metal, small amounts of $\mathrm{Mg}$ and Be can be added. This can not only improve the resistance to intergranular corrosion [54] but can also improve the cleanliness of the filler metal, ensuring the quality and reliability of the brazed joint.

\subsubsection{Flux-Cored Copper Filler Metal}

Brass filler metal and copper-based high-temperature filler metal have broad application prospects. Researchers at Zhengzhou Research Institute of Mechanical Engineering created a brass flux-cored brazing filler metal with its own reducing agent and glidant [55]. The brazing filler alloy shell is a spiral lap-joint tubular structure, wrapping the brazing wire with elements such as Sn, Ni and Si added and the inner mixed flux made of copper brazing flux, reducing agent and glidant. When the content of alloying elements in the brazing filler alloy shell is low, the wrapped brazing alloy wire is still enough to ensure that the filler metal has excellent processability, good wettability and fluidity. Copper-phosphorus filler metal has poor plasticity, and it is difficult to process and shape. Researchers at Zhengzhou Research Institute of Mechanical Engineering [56] developed a mixed flux wrapped with pure copper tube. The internal mixed flux consisted of $\mathrm{Cu}-15 \mathrm{P}$ master alloy powder, Ag powder, Sn powder and flux powder. The composite flux-cored method solved the problems of poor flowability and low brazing seam strength during brass brazing and overcame the difficulty of processing copper-phosphorus-tin brazing wire with high-phosphorus via the traditional preparation techniques. In addition, Hangzhou Huaguang Welding New Material Co., Ltd. disclosed three invention patents related to flux-cored copper filler metal [57-59], including composite-flux-cored copper brazing rings and copper brazing wires. The filler core wire can appropriately reduce the thickness of the shell, which is beneficial to processing and forming. It can also improve the fluidity of the flux, conducive to the spreading and wetting of the filler metal.

\subsubsection{Flux-Cored Silver Filler Metal}

Silver filler metals have been widely used because of their excellent wettability and corrosion resistance. Due to the difference in processability, the development of fluxcored silver filler metal lagged behind that of flux-cored aluminum filler metal. Recently, however, with the continuous transformation and upgrading of China's equipment manufacturing industry, flux-cored silver filler metal has developed rapidly in the direction of low cost $[60,61]$, high quality and automation. In addition to the conventional circular cross-section filler metal [62], the current form of flux-cored silver filler metal includes semi-closed filler metal, with a C-shaped hollow cylinder in the cross-section [63], and seamless cored silver filler metal with an oval cross-section [64].

Metal elements such as $\mathrm{Sn}, \mathrm{Ni}$ and $\mathrm{Si}$ can be added to the flux in the form of a master alloy to improve the brazing performance of the flux-cored silver filler metal $[13,65]$. Belohlav et al. [66] created a 30Ag flux-cored silver filler metal containing 2 wt.\% Ni. 
They showed that the addition of Ni can enhance the corrosion resistance of the interface, improve the wettability of the filler metal and increase the strength of the brazing joint. Xue et al. [17] prepared BAg30CuZn flux-cored brazing filler metal containing $\mathrm{Ni}$ and found that when the Ni content was above $2.5 \%$, the brazing filler metal could be directly prepared by continuous cold rolling without heat treatment. The team also prepared $17 \mathrm{AgCuZnSn}$ filler metal with a low Ag content by adding rare-earth Ce and Ga elements, which provided data support for the development of low-Ag flux-cored filler metal [67].

At present, flux-cored silver filler metal is mainly used to braze pipes in the refrigeration industry [16], and its feasibility to replace solid silver filler metal has been verified by more than a dozen companies. Researchers at Zhengzhou Research Institute of Mechanical Engineering developed BAg30CuZnSn flux-cored filler metal to meet the urgent requirement for automatic brazing of refrigeration, rail transit and other pipeline components, for which automatic wire feeding induction brazing technology and automatic collar brazing technology are well suited. Figure 8 presents a comparison of flux-cored/solid filler metal brazing effects. It can be seen that the joints of welds brazed with flux-cored filler metal are smooth and without redundancy. According to Haier's production and manufacturing site verification, as shown in Table 1, the average maintenance dosage of traditional solid silver filler metal for a single joint is $0.5 \mathrm{~g} /$ point, while the average single-point filler metal consumption of composite filler metal is reduced to $0.35 \mathrm{~g} /$ point. Compared with traditional solid silver filler metal, composite filler metal can save $30 \%$ of materials.

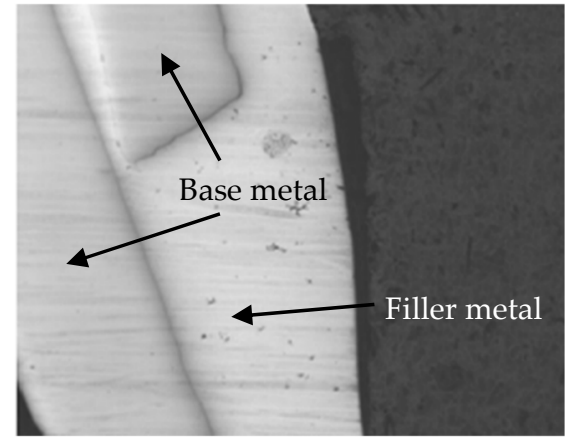

(a)

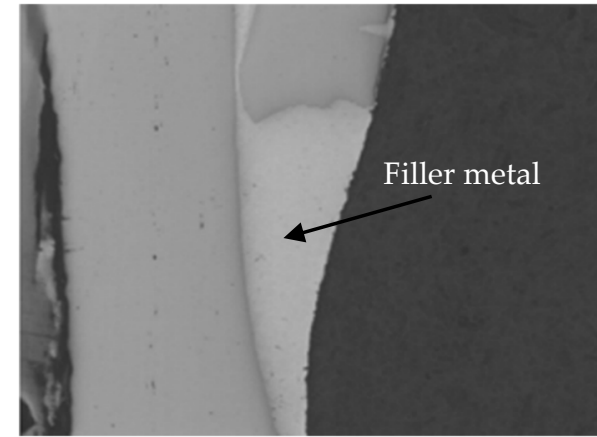

(b)

Figure 8. Comparison of brazed joints with different kinds of brazing filler metal [68]: (a) solid silver filler metal; (b) flux-cored silver filler metal.

Table 1. Consumption of filler alloy and flux in a single brazed joint.

\begin{tabular}{ccc}
\hline Single Brazed Joint & Solid Filler Metal & Flux-Cored Filler Metal \\
\hline Consumption of filler alloy & $0.5 \mathrm{~g}$ & $0.35 \mathrm{~g}$ \\
Consumption of flux & $0.1 \mathrm{~g}$ & $0.05 \mathrm{~g}$ \\
\hline
\end{tabular}

\section{Research on Flux-Coated Brazing Filler Metals}

With the development of brazing technology, the structure of brazing material has become increasingly diversified. Preformed filler metals are adapted to the development trend of automation and intelligent production. Coating a layer of flux on the surface of the preformed filler metals as a coating filler metal has become another alternative technology option for the preparation of emission reduction brazing material. The shapes of preformed flux-coated filler metals include strip, ring, square, trapezoid, sector and arc, among which the ring is the most common. The coating of conventional flux-coated filler metal is prepared by pressure coating, and the coating layer mainly includes adhesive, plasticizer and flux. The development of the adhesive is the key process and difficulty in the preparation of the flux-coated filler metal. The adhesives are mainly divided into organic and inorganic types. Most of the conventional coated electrodes contain organic 
adhesive [68], which pollutes the environment and damages human health. For example, to apply the solution flux on the surface of filler metals, US. Lucas Co. uses a large amount of organic adhesive. During the brazing process, the organic adhesive decomposes and carbonizes by heat, which produces harmful gases, as shown in Figure 9a. Researchers at Zhengzhou Research Institute of Mechanical Engineering developed a variety of fluxcoated brazing filler metal rings $[69,70]$ without organic adhesive, as shown in Figure $1 \mathrm{~b}$. These reduce the labor intensity of the brazing process and environmental pollution (as shown in Figure 9b).

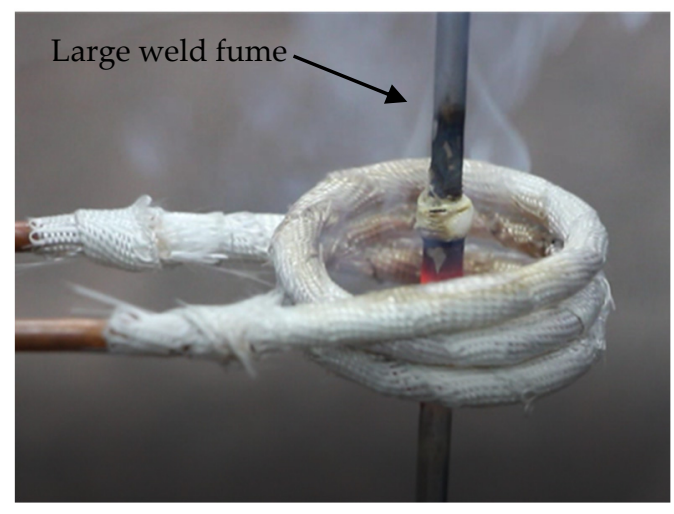

(a)

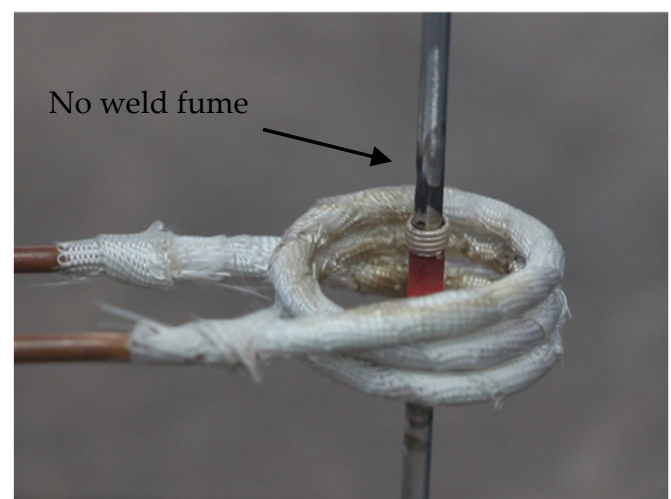

(b)

Figure 9. Comparison of weld fumes during induction brazing of a bundy tube with different kinds of flux-coated silver filler metal rings: (a) filler metal ring with organic adhesive; (b) filler metal ring without organic adhesive.

\subsection{Preparation of Flux-Coated Filler Metals}

Figure 10 shows the process flow chart for the preparation of a flux-coated filler metal ring. The coating process marked with a red star is the key process [68]. The coating technology of flux-coated filler metal rings mainly applies the dip-coating method, melt adhesion method, high-pressure airless spraying method, air spraying method or drumcoating method [71]. The dip-coating method directly immerses the filler metal in the coating paste. The melting adhesion method heats the powder flux so that it can be firmly attached to the filler metals as the coating. Compared with the air spraying method, the high-pressure airless spraying method has a higher coating efficiency and paste filler metal utilization and can quickly create a thick and dense coating. The drum-coating and highpressure airless spraying methods are both relatively mature methods for high-quality flux-coated filler metals. The drum-coating method is expensive and requires special equipment. The high-pressure airless spraying method can be modified on the basis of existing equipment, low costs and broad application prospects. The new environmentally friendly flux-coated filler metal rings [72,73] prepared by Zhengzhou Research Institute of Mechanical Engineering via the high-pressure airless spraying method have an excellent brazing performance at a competitive price.

\subsection{Application of Flux-Coated Filler Metals}

In recent years, automatic flame-brazing technology (Figure 11) has developed rapidly. The technology simulates and optimizes manual brazing actions through mechanical programming, which has the advantages of a stable production rhythm and quality. For the air-conditioning pipeline, the internal structure is complicated. There are precision valve bodies, wires, sound insulation cotton, nameplate barcodes, etc., where flame brazing is not suitable, and high-frequency brazing is required. Compared with flame brazing, induction brazing has the advantages of higher energy utilization, rapid heating, lower energy consumption, less pollution and a smaller heat-affected zone. Figure 12 shows the application of the multiple flux-coated filler metal rings [74] developed by Zhengzhou Research Institute of Mechanical Engineering in the pipeline brazing of an air-conditioning distributor. The multicircle flux-coated filler metal ring can increase the contact area be- 
tween the filler metal ring and the workpiece to be welded, improving the heat conduction velocity and avoiding overheating or overburning of the workpiece to be welded. Compared with solid filler metals, it can reduce the usage of flux and protect the environment. Automatic brazing technology, meanwhile, can realize the automatic, quantitative and accurate addition of filler metals and flux, avoiding the waste caused by excessive use of flux, significantly reducing environmental pollution, ensuring the consistency of the brazing and the stability of the joint quality and avoiding excessive dependence on the skill level of the operator.

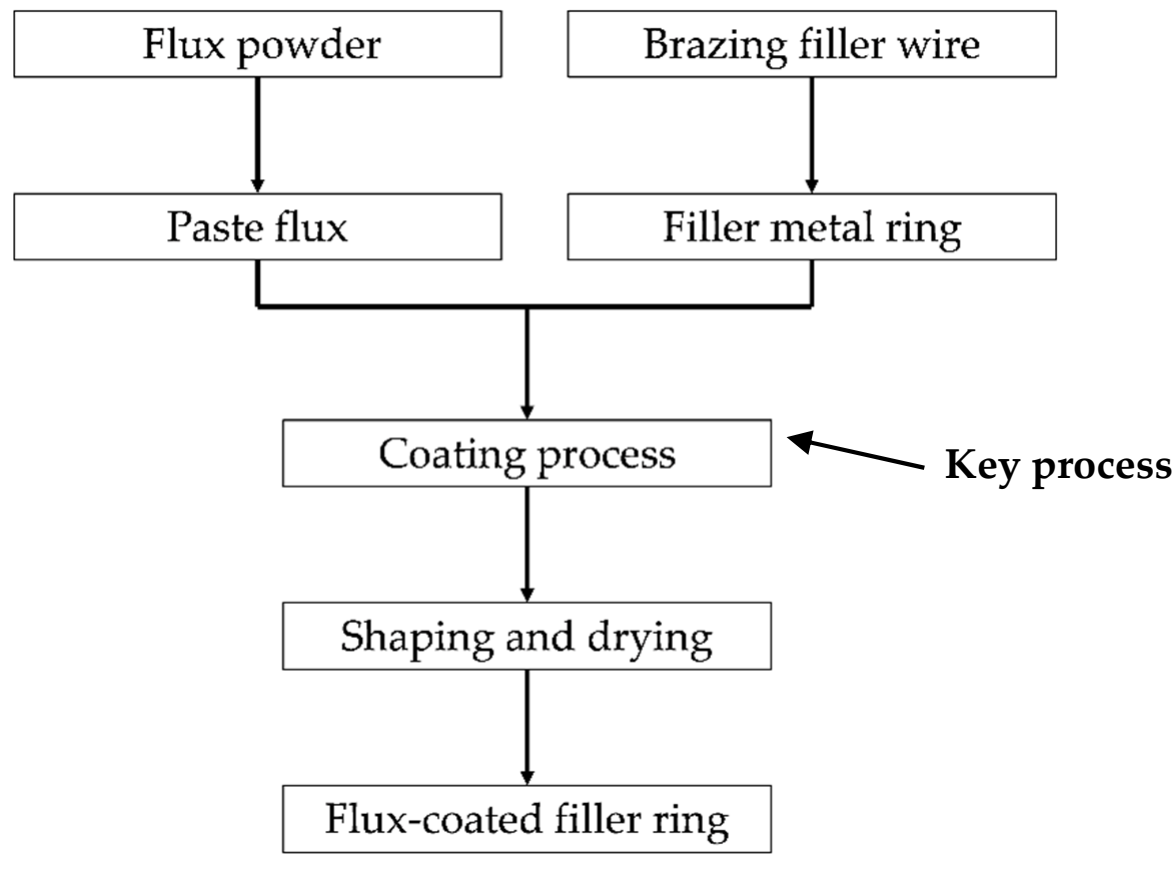

Figure 10. Process flow chart for the preparation of a flux-coated filler metal ring [68].

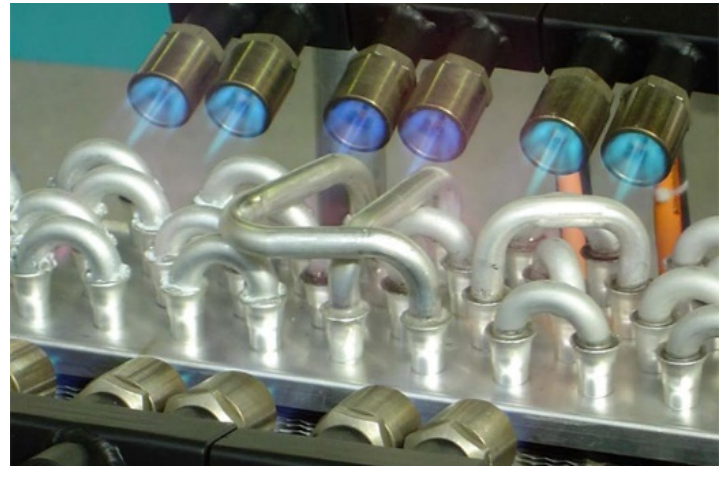

(a)

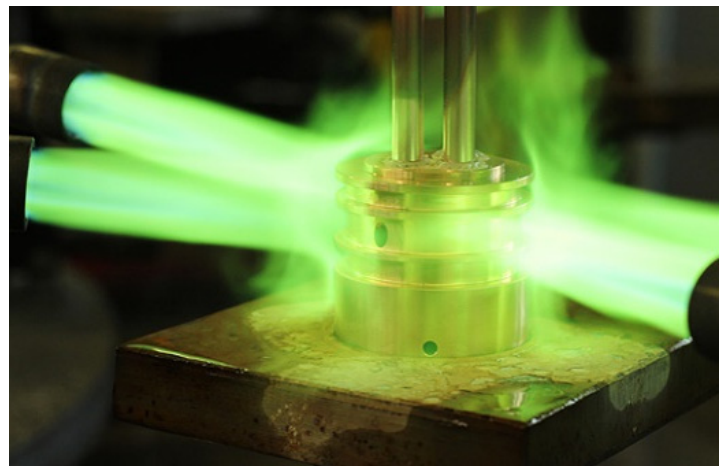

(b)

Figure 11. Automatic flame-brazing technology for: (a) refrigeration and air conditioning; (b) automotive industry.

It can be seen from Figure 12 that the flux-coated filler metal ring has a good filling ability during melting and excellent formability during solidification. At present, the flux-coated filler metal ring developed by Zhengzhou Research Institute of Mechanical Engineering has been applied in batches in the refrigeration industry and has been widely used in the vehicle, tool and other industries. Refrigerators, freezers, air conditioners and other household appliances, as well as refrigeration accessories (four-way valve, stop valve, etc.), mainly use flux-coated cadmium-free silver filler metal rings and flux-coated copper-phosphorus filler metal rings, which have been used by Haier, Hisense, Midea, Gree, TCL, Meiling, Xinfei, Sanhua and other enterprises for many years. 


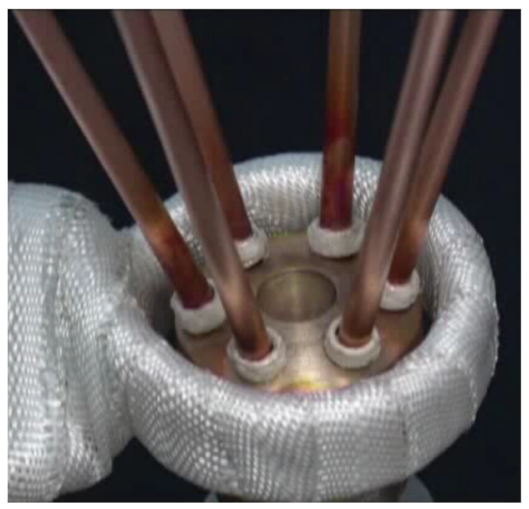

(a)

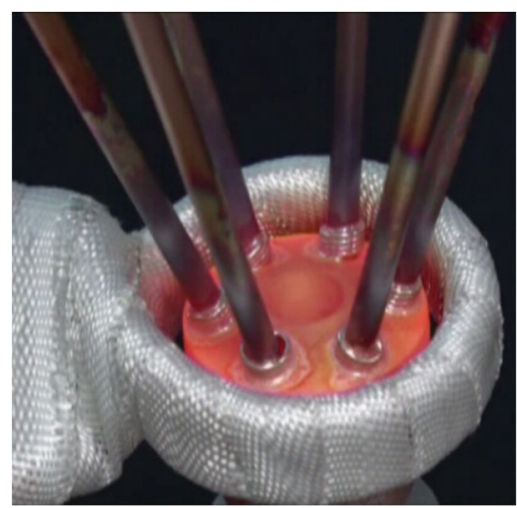

(c)

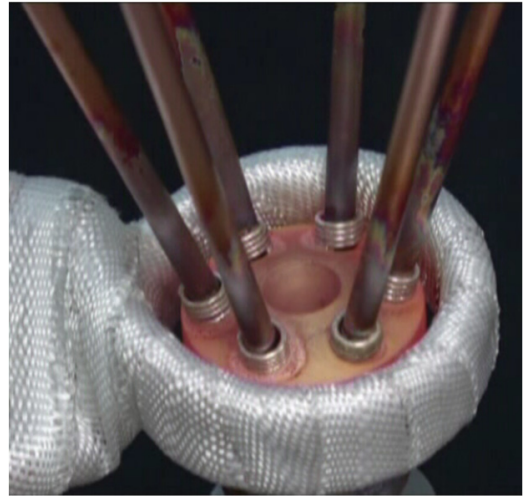

(b)

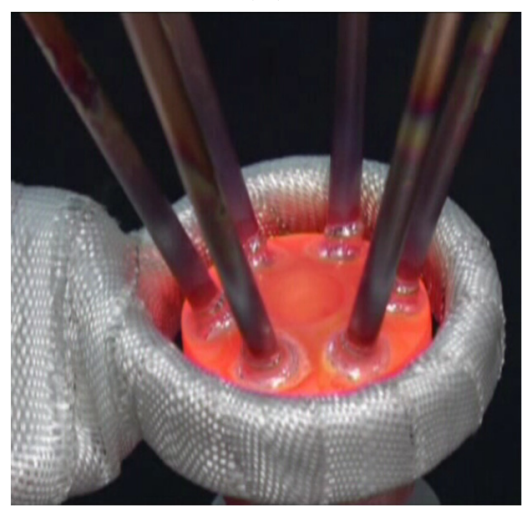

(d)

Figure 12. Induction brazing process of flux-coated filler metal ring: (a) assembly of flux-coated filler metal ring; (b) melting of flux and removing oxide film; (c) melting of filler alloy and filling seam; (d) solidification of filler alloy and forming.

\section{Research on Powder Metallurgy Filler Metals}

In addition to the common flux-cored filler metals and flux-coated filler metals, the composite brazing materials with flux also include powder metallurgy brazing filler metals. As early as 2004, Sunkwang Brazing Filler Metal Co., Ltd. [75] created two kinds of powder metallurgy brazing filler metals. The brazing filler alloys are Al-Si alloys or $\mathrm{Zn}-\mathrm{Al}$ alloys, and the fluxes are potassium fluoroaluminate and cesium fluoroaluminate. The specific forming process is shown in Figure 13. Powder metallurgy brazing filler metals successively go through the processes of weighing (10-40\% based on the weight of the flux), powder mixing, powder forging, hot extrusion and cutting. A photo of the powder metallurgy filler ring is shown in Figure 1c, and the microstructure is shown in Figure 14. The flux is evenly distributed in the matrix, which can improve the moisture absorption resistance of the flux, reduce the amount of flux and simplify the brazing process.

Yantai Guguang Welding Materials Co., Ltd. [76] shared a preparation method for a low-temperature copper-aluminum brazing filler metal. Different compositions composed of $\mathrm{Al}, \mathrm{Cu}$ and $\mathrm{Si}$ are mixed in proportion, and medium-temperature noncorrosive aluminum flux powder is added. After ball milling for several hours, it is extruded in a 300-ton press. The temperature of the extrusion process is controlled at $200-350{ }^{\circ} \mathrm{C}$. The protective gas is carbon dioxide or nitrogen. Changzhou Sinleh Metal New Material Co., Ltd. [77] also uses a similar processing technology to prepare $\mathrm{Zn}$-Al-based powder metallurgy brazing filler metals. The brazing filler metal and flux are evenly mixed, and the product's performance is stable and consistent. 


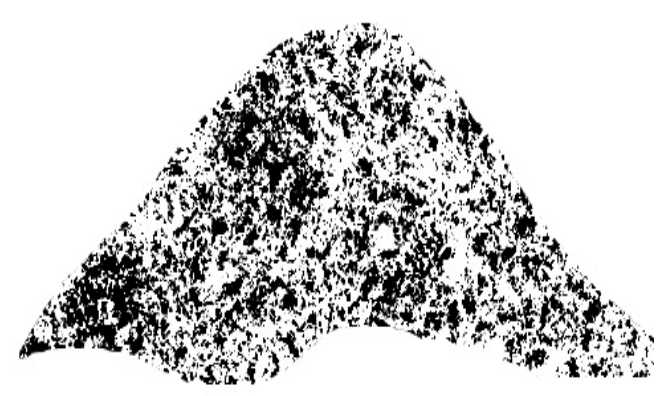

(a)

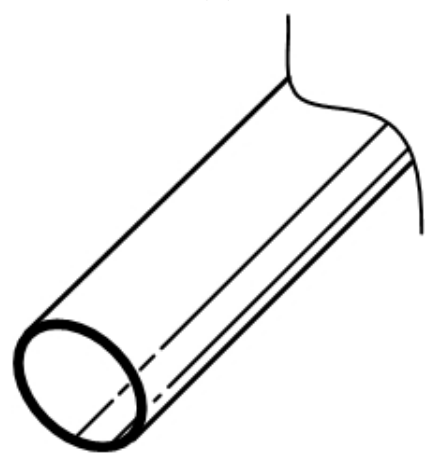

(c)

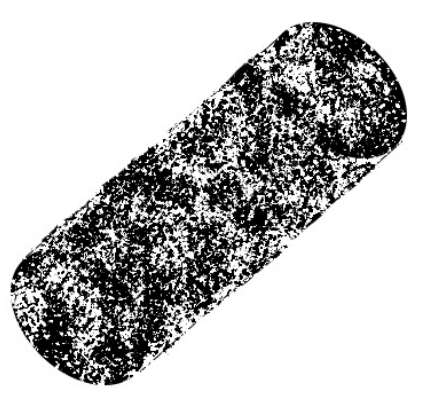

(b)

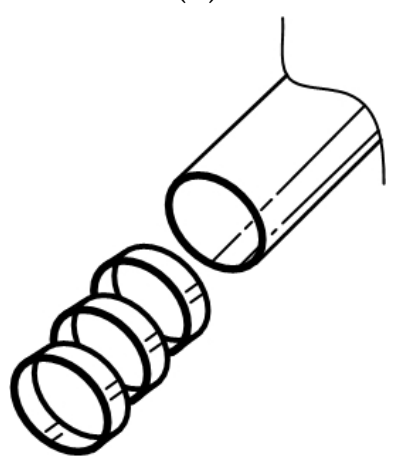

(d)

Figure 13. Manufacturing processes of ring-type brazing filler metal with flux [75]: (a) mixing of filler alloy powder and flux powder; (b) powder forging of mixed powders; (c) hot extrusion into a pipe; (d) cutting.

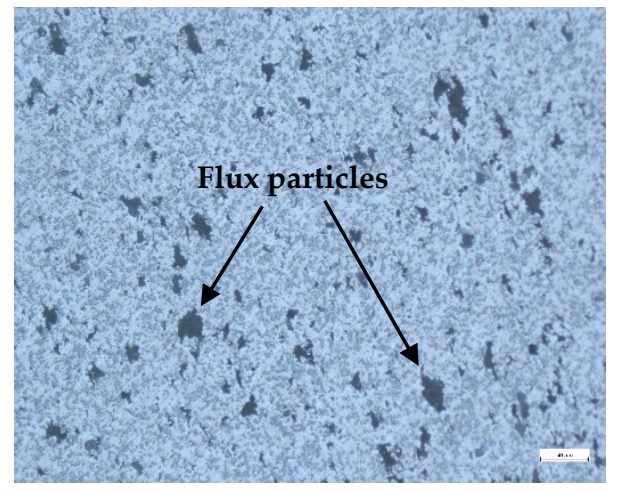

Figure 14. Microstructure of the composite brazing filler metal prepared by powder metallurgy.

Differently from the above process, Li et al. [78] of Zhengzhou Research Institute of Mechanical Engineering developed a kind of filler metal by the hot-pressing method. The brazing filler alloy particles and the flux powder were mixed firstly, loaded into a hot-pressing mold and finally pressed and sintered into a special shape of composite filler metal. A schematic diagram of the hot-pressing mold is shown in Figure 15. Firstly, the Nocolok flux and Al-12Si filler metal powder are dried $\left(100^{\circ} \mathrm{C}, 1 \mathrm{~h}\right)$ to remove water vapor. Secondly, $15 \mathrm{wt} . \%$ flux and $85 \mathrm{wt} . \%$ filler metals are mixed and ground in a KQM-X4C/B planetary four-head fast ball mill. Then, the mixed powder of flux and brazing filler metal is loaded into the cavity of the pressing die through the powder charging shoe. The upper pressing head reciprocates and drives a punch to compact the mixed powder and remove the gas in the cavity. The above operation is repeated until the aluminum brazing ring with the required thickness is obtained. Finally, it is quickly heated to a certain temperature under a certain pressure for sintering, and the self-fluxing aluminum brazing ring with the required specification is obtained through the ejection mechanism. 


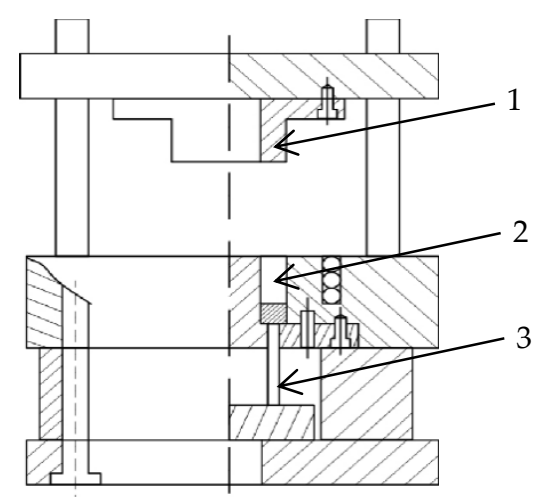

Figure 15. Schematic diagram of hot-pressing mold [79]: 1, convex module; 2, mold cavity; 3, ejection mechanism.

Li et al. also systematically studied the effects of pressure [79], as well as temperature [80], time [81] and other parameters of hot-pressure sintering on the microstructure, wettability and brazing properties of powder metallurgy brazing filler metal, revealing that the hot-pressure sintering mechanism of filler metal rings solved the problems of low toughness and too many pores that are found in traditional extruded filler metals ring. Filler metal rings prepared under the optimized process have good wettability to LF21 aluminum alloy, and the tensile strength of the brazed joint is about $60 \mathrm{MPa}$.

\section{Conclusions and Prospects}

Composite brazing filler metal is an important means of practicing green and automated brazing due to less flux and accurate brazing reaction. At present, there are still problems in the field of composite brazing filler metal, such as a lack of technology research and independent innovation and mismatch between brazing materials and manufacturing equipment, which severely restricts the application and promotion of composite brazing filler metal. It is necessary to develop new component brazing materials, and the corresponding processing and manufacturing technology also urgently needs to be improved.

In the past few decades, scientific research institutes, enterprises and universities worldwide have been committed to the research into and application of green and efficient brazing materials, continuously promoting the development of green brazing technology. They have successively invented flux-cored brazing filler metals, coated brazing filler metals and powder metallurgy brazing filler metals, as well as a series of original technologies such as particle reinforcement, surface activation and pilot wetting, in line with the current development trend and market demand of advanced manufacturing industry.

In reviewing the development of composite brazing filler metal, combined with the increasingly stringent demand for brazing, we look forward to a future research and development focus on composite brazing filler metal. Material genome technology [82] has been proposed as a means of designing the compositions of brazing filler metals and developing low-silver cadmium-free filler metals [29] with high activity flux and low emissions. Atomistic theoretical and theoretical-leading-to-experimental realization studies (such as the first-principles calculation method based on density functional theory) should be widely promoted on novel technological brazing filler materials with prefabricated properties. Researchers are continuously innovating the processing and preparation technology of composite filler metals, such as friction stir processing technology and electromagnetic plasticization technology, to create new powder brazing filler metal-forming technologies. Research teams are controlling the shape and improving the development of continuous plate-packed and barrel-packed flux-cored composite filler metals, with excellent surface quality resulting, to replace the traditional manual-strip filler metals and accelerate the process of automation and advent of intelligent brazing [83]. 
Author Contributions: Conceptualization, W.L. and S.G.; methodology, B.W.; software, B.W.; validation, B.W. and M.W.; formal analysis, S.Z.; investigation, B.W.; resources, B.W.; data curation, S.Z.; writing-original draft preparation, B.W.; writing-review and editing, M.W.; visualization, P.Y.; supervision, S.Z.; project administration, S.G.; funding acquisition, S.X. and W.L. All authors have read and agreed to the published version of the manuscript.

Funding: This research was funded by National Natural Science Foundation of China (Grant No. 51975284), Henan Province's Major Key Technology Demand Unveiling and Tackling Key Projects (Grant No. 191110111000) and the 2020 Ningbo “3315 Talent Introduction Plan” Innovative Team (C-Class).

Data Availability Statement: The data could be obtained from the corresponding author.

Acknowledgments: The authors sincerely acknowledge the financial supports by National Natural Science Foundation of China (Grant No. 51975284), the Henan Province's Major Key Technology Demand Unveiling and Tackling Key Projects (Grant No. 191110111000) and the 2020 Ningbo "3315 Talent Introduction Plan" Innovative Team (C-Class). The authors thank Baolai He (from Ningbo Shengli Fatener Co., Ltd., Ningbo, China) for technical support.

Conflicts of Interest: The authors declare no conflict of interest.

\section{References}

1. Comprehensive Technical Report of the 24th Beijing Essen Welding and Cutting Fair; Chinese Mechanical Engineering Society: Beijing, China, 2019. Available online: http:/ / www.beijing-essen-welding.com/file/tec/\%E7\%AC\%AC24\%E5\%B1\%8A \%E5\%8C \%97 \%E4\%BA\%AC\%C2\%B7\%E5\%9F\%83\%E6\%A3\%AE\%E7\%84\%8A\%E6\%8E\%A5\%E4\%B8\%8E\%E5\%88\%87\%E5\%89\%B2\%E5\%B1 \%95\%E8\%A7\%88\%E4\%BC \%9A\%E5\%B1\%95\%E4\%BC\%9A \%E7\%BB\%BC\%E5\%90\%88\%E6\%8A\%80\%E6\%9C\%AF\%E6\%8A \%A5 \%E5\%91\%8A.pdf (accessed on 20 July 2021).

2. Zhi, W.N.; Zheng, Y.; Ji, H.H.; Hao, Y.; Jian, Y.; Chen, S. Interfacial structure and properties of Cu/ Al joints brazed with Zn-Al filler metals. Mater. Charact. 2018, 138, 78-88. Available online: https://www.sciencedirect.com/science/article/abs/pii/S10445 80317325317?via\%3Dihub (accessed on 31 July 2021).

3. Han, L. Research on Corrosion Resistant Aluminum Alloy with Low Melting Point. Master's Thesis, Hefei University of Technology, Hefei, China, 2014.

4. Xue, S.B.; Wang, B.; Zhang, L.; Long, W.M. Development of green welding technology in China during the past decade. Mater. Rep. 2019, 33, 2813-2830. [CrossRef]

5. Yu, H.; Zhang, L.L.; Cai, F.F.; Zhong, S.; Ma, J.; Zhang, Y.; Si, A.H.; Wei, S.Z.; Long, W.M.; Stock, H.R.; et al. Interface microstructure and growth mechanism of brazing Cu/Al joint with BAl88Si filler metal. Vacuum 2020, 181, 109641. Available online: https:/ / www.sciencedirect.com/science/article/pii/S0042207X20305030 (accessed on 31 July 2021). [CrossRef]

6. Yu, H.; Zhang, L.L.; Cai, F.F.; Zhong, S.J.; Ma, J.; Bao, L.; Jiu, Y.T.; Hu, B.L.; Wei, S.Z.; Long, W.M. Microstructure and mechanical properties of brazing joint of silver-based composite filler metal. Nanotechnol. Rev. 2020, 9, 1034-1043. [CrossRef]

7. Huang, S.; Long, W.M.; Lu, Q.B.; Jiu, Y.T.; Zhong, S.J.; Bao, L.; Zhao, Y. Research on the corrosion resistance of Cu-Al joints brazed with flux-cored Zn-2Al filler metal. Mater. Res. Express. 2019, 6, 056560. [CrossRef]

8. Cheng, Z. Calculation Study on the Properties of Compounds in Sn Solder. Ph.D. Thesis, China Academy of Machinery Science and Technology, Beijing, China, 2020.

9. Schmidt, S.; Greczynski, G.; Goyenola, C.; Gueorguiev, G.K.; Czigány, Z.; Jensen, J.; Ivanov, I.G.; Hultman, L. CF(x) thin solid films deposited by high power impulse magnetron sputtering: Synthesis and characterization. Surf. Coat. Technol. 2011, 206, 646-653. [CrossRef]

10. Bakoglidis, K.D.; Palisaitis, J.; dos Santos, R.B.; Rivelino, R.; Persson, P.O.Å.; Gueorguiev, G.K.; Hultman, L. Self-healing in carbon nitride evidenced as material inflation and superlubric behavior. ACS Appl. Mater. Interfaces 2018, 10, 16238-16243. [CrossRef]

11. Högberg, H.; Lai, C.-C.; Broitman, E.; Ivanov, I.G.; Goyenola, C.; Näslund, L.-Å.; Schmidt, S.; Hultman, L.; Rosen, J.; Gueorguiev, G.K. Reactive sputtering of CSx thin solid films using CS2 as precursor. Vacuum 2020, 182, 109775. Available online: https://www.sciencedirect.com/science/article/pii/S0042207X20306369 (accessed on 31 July 2021). [CrossRef]

12. Lv, X.C.; Sun, X.M.; Song, B. Development of brazing and soldering filler metal industry and brazing and soldering standardized requirement. Weld. Dig. Mach. Manuf. 2019, 3, 13-17.

13. Dong, B.W.; Long, W.M.; Zhong, S.J.; Dong, X.; Lv, D.F. Research progress on flux-cored brazing filler metals. Mater. Mech. Eng. 2019, 43, 1-5. [CrossRef]

14. Darling, C.F. Advantages of flux cored alloys for open air brazing: Flux cored wire creates a high-strength joint while limiting the amount of flux used and creating less waste. Weld. J. 2008, 87, 41-44. Available online: https://app.aws.org/bsmc/wj200803_41 .pdf (accessed on 31 July 2021).

15. Lucas-Milhaupt, Inc. Flux Cored Preforms for Brazing: U.S. US RE42329E, 10 May 2011. Available online: https://patentimages. storage.googleapis.com/9f/d5/5e/6852869339675f/USRE42329.pdf (accessed on 20 July 2021). 
16. Zhao, J.C.; Lv, D.F.; Long, W.M.; Zhong, S.J.; Zhang, Q.K.; Zhang, L. Manufacturing technology and application prospect of flux cored silver filler metal. Weld. Join. 2016, 5, 9-11. [CrossRef]

17. Zhang, T. Effect of Ni on the Manufacture of BAg30CuZn Flux Cored Filler Metal and Its Brazing Performance. Master's Thesis, Nanjing University of Aeronautics and Astronautics, Nanjing, China, 2016.

18. Zhengzhou Research Institute of Mechanical Engineering Co., Ltd. Flux-Cored Silver Brazing Filler Metal and Preparation Method Thereof: China. ZL 201510269666.1, 31 October 2017. Available online: https:/ / patentimages.storage.googleapis.com/ 1e/ea/97/edc78fb62f4e3e/CN104907727B.pdf (accessed on 20 July 2021).

19. Chen, Y.L. Research Brazed Al-Si, Al-Si-Cu Alloy Flux-Cored Wires. Master's Thesis, Beijing University of Technology, Beijing, China, 2014.

20. Beijing Non-Ferrous Metals and Rare Earth Research Institute. Beijing University of Technology. Method for Manufacturing Seamless Flux-Cored Al-Si-Cu Brazing Wires: China. ZL 201310532809.4, 2 December 2015. Available online: https:/ / patentimages.storage.googleapis.com/6e/a6/28/15edc4d486ac9a/CN103521943B.pdf (accessed on 20 July 2021).

21. Shanghai Longshuo Welding Material Co., Ltd. Flux-Cored Compostie Aluminum Welding Wire and Preparation Method Thereof: China. ZL 201310553434.X, 10 February 2016. Available online: https://patentimages.storage.googleapis.com/6e/c2/c7 /9040024260140a/CN103612026B.pdf (accessed on 20 July 2021).

22. Long, W.M. Research on Production and Application of the Flux-Cored Aluminium Welding Materials. Master's Thesis, Tsinghua University, Beijing, China, 2002.

23. FoShan Yihong Welding Co., Ltd. Silver-Based Flux-Cored Wire and Manufacturing Method Thereof: China. ZL 201110435173.2, 12 November 2014. Available online: https:/ / patentimages.storage.googleapis.com/06/9c/ce/51c9fe3508366a/CN102513726B. pdf (accessed on 20 July 2021).

24. Shanghai SMIC Wilco Welding Material Co., Ltd. Method for Manufacturing Seamless Flux-Cored Aluminum Alloy Wire: China. CN 200610118399.9, 28 May 2008. Available online: https:/ / patentimages.storage.googleapis.com/a5/de/4b/0037b6d7778488 /CN101185997A.pdf (accessed on 20 July 2021).

25. Liu, P.F.; Zhang, X.; Yao, R.G. Development of manufacturing technology for seamless flux-cored welding wire. MW Met. Form. 2011, 10, 18-20.

26. Liu, L.Y. Study on Seamless Flux Cored Welding Wire Of 0.5Ni System with Super Low Hydrogen and High Toughness. Master's Thesis, Tianjin University, Tianjin, China, 2016.

27. China Association of Machinery Manufacturing Technology. T/CAMMT 14-2019, Flux-Cored Aluminum Brazing Filler Metal. Available online: https:/ /www.doc88.com/p-3129197844490.html?r=1 (accessed on 20 July 2021).

28. Wang, X.X.; Zhang, G.X.; Long, W.M.; Shen, Y.X.; Pei, Y.Y.; Lv, D.F. Experimental research of tin brush electro-plated on Ag45CuZn brazing filler metal. Rare Met. Mater. Eng. 2013, 42, 2394-2399.

29. Wu, J.; Xue, S.B.; Yao, Z.; Long, W.M. Study on microstructure and properties of $12 \mathrm{Ag}-\mathrm{Cu}-\mathrm{Zn}-\mathrm{Sn}$ cadmium-free filler metals with trace in addition. Crystals 2021, 11, 557. Available online: https:/ / www.mdpi.com/2073-4352/11/5/557 (accessed on 31 July 2021). [CrossRef]

30. Long, W.M.; Zhang, G.X.; Zhang, Q.K. In situ synthesis of high strength Ag brazing filler metals during induction brazing process. Scr. Mater. 2016, 110, 41-43. [CrossRef]

31. Long, W.M.; Dong, B.W.; Zhang, Q.K.; He, P.; Xue, P. Brazing of carbon steel using Cu-P brazing filler metals based on guide wetting of Ag alloys. Trans. China Weld. Inst. 2017, 38, 1-4.

32. Long, W.M.; Lu, Q.B.; He, P.; Xue, S.B.; Wu, M.F.; Xu, P. In situ synthesis of Al-Si-Cu alloy during brazing process and mechanical property of brazing joint. J. Mater. Eng. 2016, 44, 17-23. [CrossRef]

33. Harbin Institute of Technology (Weihai). Flux-Cored Wire for Aluminum/Steel Welding-Brazing: China. ZL 201510401274.6, 19 April 2017. Available online: https:/ / patentimages.storage.googleapis.com/16/3f/c2/d78a624864ff0c/CN104972242B.pdf (accessed on 20 July 2021).

34. Zhengzhou Research Institute of Mechanical Engineering Co., Ltd. Flux-Cored Aluminum Welding Wire with Reinforced Metallic Particles: China. ZL 201210523509.5, 4 March 2015. Available online: https://patentimages.storage.googleapis.com/af/9d/93/5 e771a8e883492/CN102935562B.pdf (accessed on 20 July 2021).

35. Zhengzhou Research Institute of Mechanical Engineering Co., Ltd. Flux-Cored Welding Rod for Preventing Flux from Loss: China. ZL 201510565379.5, 17 May 2017. Available online: https://patentimages.storage.googleapis.com/a3/ec/49/74156bdb3 03469/CN105108378B.pdf (accessed on 20 July 2021).

36. Pu, J.; Xue, S.B.; Zhang, L.; Wu, M.F.; Long, W.M.; Wang, S.Q.; Qian, S.J.; Lin, T.S. Effect of $\mathrm{CeO}_{2}$ on wettability of Ag30CuZnSn flux cored brazing filler metal and microstructure and properties of brazed joint. Mater. Rep. 2021, 35, 8134-8139. [CrossRef]

37. Pu, J.; Zhang, L.; Wu, M.F.; Long, W.M.; Zhong, S.J.; Lin, T.S. Effect of SnAg1.0Cu0.5 on the wettallity of Ag30CuZnSn flux cored brazing filler and mechanical properties of its brazed joints. Trans. China Weld. Inst. 2021, 42, 58-64. [CrossRef]

38. Yao, Z.; Xue, S.B.; Zhang, J.X. Effect of various nanoparticles $\left(\mathrm{GaF}_{3}, \mathrm{ZnF}_{2}, \mathrm{Zn}\left(\mathrm{BF}_{4}\right)_{2}\right.$ and $\left.\mathrm{Ga}_{2} \mathrm{O}_{3}\right)$ additions on the activity of $\mathrm{CsF}-\mathrm{RbF}-\mathrm{AlF}_{3}$ flux and mechanical behavior of $\mathrm{Al} /$ Steel brazed joints. Crystals 2020, 10, 683. Available online: https: //www.mdpi.com/2073-4352/10/8/683 (accessed on 31 July 2021). [CrossRef]

39. Yao, Z.; Xue, S.B.; Yang, J.L.; Zhang, J.X. Inducing the effect of a $\mathrm{Ga}_{2} \mathrm{O}_{3}$ nano-particle on the CsF-RbF-AlF $\mathrm{flux}_{3}$ for brazing aluminum to carbon steels. Crystals 2020, 10, 183. Available online: https:/ / www.mdpi.com/2073-4352/10/3/183 (accessed on 31 July 2021). [CrossRef] 
40. Pu, J.; Xue, S.B.; Wu, M.F.; Long, W.M.; Wang, S.Q.; Lin, T.S. Effect of $\mathrm{Ga}_{2} \mathrm{O}_{3}$ on microstructure and properties of brazed joints obtained by Ag30CuZnSn flux cored brazing filler metal and brass. Trans. China Weld. Inst. 2020, 41, 46-52.

41. Goyenola, C.; Gueorguiev, G.K.; Stafström, S.; Hultman, L. Fullerene-like CSx: A first-principles study of synthetic growth. Chem. Phys. Lett. 2011, 506, 86-91. Available online: https://www.sciencedirect.com/science/article/pii/S0009261411002351 (accessed on 31 July 2021). [CrossRef]

42. China Innovation Academy of Intelligent Equipment Co., Ltd. Aluminum Powder-Containing Flux-Cored Silver Brazing Filler Metal for Brazing Hard Alloy and Preparation Method Thereof: China. CN 202011566415.7, 9 April 2021. Available online: https:/ / patentimages.storage.googleapis.com/18/90/bc/bd43b7c4440a3f/CN112621014A.pdf (accessed on 20 July 2021).

43. China Innovation Academy of Intelligent Equipment Co., Ltd. Flux-Cored Aluminum Brazing Filler Metal and Preparation Method Thereof: China. CN 202011566418.0, 9 April 2021. Available online: https:/ / patentimages.storage.googleapis.com/ba/ 4d/43/1376c258fdb0d5/CN112621015A.pdf (accessed on 20 July 2021).

44. China Innovation Academy of Intelligent Equipment Co., Ltd. Flux-Cored Copper Brazing Filler Metal and Preparation Method Thereof: China. CN 202011563528.1, 9 April 2021. Available online: https://patentimages.storage.googleapis.com/d8/1c/4d/48 d92e8a9d8e7c/CN112621019A.pdf (accessed on 20 July 2021).

45. Santos, R.; Rivelino, R.; Mota, F.; Gueorguiev, G.; Kakanakova-Georgieva, A. Dopant species with Al-Si and N-Si bonding in the MOCVD of AlN implementing trimethylaluminum, ammonia and silane. J. Phys. D Appl. Phys. 2015, 48, 295104. [CrossRef]

46. Zhou, L.; Li, Z.Y.; Zhao, H.Y.; Huang, Y.X.; Xie, Y.; Tao, J.; Feng, J.C. TIG welding-brazing for Al/Cu dissimilar metals using filler material. Trans. China Weld. Inst. 2016, 37, 17-20.

47. Li, L.Q.; Xia, H.B.; Tan, C.W.; Ma, N.S. Effect of groove shape on laser welding-brazing Al to steel. J. Mater. Process. Technol. 2018, 252, 573-581. [CrossRef]

48. Zhang, M. Effect and Mechanism of Al and Ag on Zn-Al Filler Metal. Doctoral Thesis, Nanjing University of Aeronautics and Astronautics, Nanjing, China, 2012.

49. Zhang, M.; Wang, P.F.; Zhang, L.C.; Xu, H.B. Effect of Al on properties of Zn-Al filler metal brazing 2A01 Al-alloy. Trans. China Weld. Inst. 2013, 34, 87-90.

50. Yang, J.L.; Xue, S.B.; Liu, H.; Xue, P.; Dai, W. Effects of Silicon on Microstructures and Properties of Al-40Zn- $x$ Si Filler Metal. Rare Met. Mater. Eng. 2016, 45, 333-338. Available online: https://www.sciencedirect.com/science/article/abs/pii/S187553721630065 0 ?via\%3Dihub (accessed on 31 July 2021).

51. Yang, J.L.; Xue, S.B.; Xue, P.; Lv, Z.P. Effect of zirconium on microstructure and properties of Zn-15Al filler metal. Trans. China Weld. Inst. 2016, 37, 61-65.

52. Wang, B.; Liu, H.; Xue, S.B.; Li, Y.; Lou, J.Y.; Lou, Y.B. Effect of rare earth Ce on microstructure and properties of Zn-22Al filler metal. Trans. China Weld. Inst. 2013, 34, 61-64.

53. Yang, J.L.; Xue, S.B.; Ji, F.; Wang, K.B.; Sun, B.; Wang, S.Q. Effect of titanium on microstructure and properties of Zn-22Al filler metals. Trans. China Weld. Inst. 2012, 33, 93-96.

54. Lv, D.F. Study on the Embrittlement Mechanism and Performance Optimization of Flux-Cored Zn-Al Filler Metal. Master's Thesis, China Academy of Machinery Science and Technology, Beijing, China, 2014.

55. Zhengzhou Research Institute of Mechanical Engineering Co., Ltd. Flux-Cored Brass Brazing Filler Metal with Reductant and Flow Aid: China. ZL 201520341120.8, 9 December 2015. Available online: https://patentimages.storage.googleapis.com/58/2e/ 28/34d6b2f34f356a/CN204843292U.pdf (accessed on 20 July 2021).

56. Zhengzhou Research Institute of Mechanical Engineering Co., Ltd. Flux-cored Cu-P-Sn Brazing Filler Metal and Preparation Method Thereof: China. ZL 201610760345.6, 7 May 2019. Available online: https:/ / patentimages.storage.googleapis.com/7b/a9 /84/e0a9af7ec02e27/CN106238947B.pdf (accessed on 20 July 2021).

57. Hangzhou Huaguang Advanced Welding Materials Co., Ltd. Equipment for Manufacturing Flux-Cored Brass Welding Wire: China. ZL 201610159711.2, 13 February 2018. Available online: https:/ / patentimages.storage.googleapis.com/19/11/0a/26f441 ab1b105b/CN105728992B.pdf (accessed on 20 July 2021).

58. Hangzhou Huaguang Advanced Welding Materials Co., Ltd. Metal-Flux-Cored Brass Filler Metal Ring and Manufacturing Method Thereof: China. ZL 201410504079.1, 1 February 2017. Available online: https://patentimages.storage.googleapis.com/67 / f8/ab/fb3bcf75da14df/CN104384758B.pdf (accessed on 20 July 2021).

59. Hangzhou Huaguang Advanced Welding Materials Co., Ltd. Single and Double Lap Flux-Cored Filler Metal Rings and Their Application Method: China. CN 201810163830.4, 13 July 2018. Available online: https:/ / patentimages.storage.googleapis.com/ 76/d5/4b/834eedf59e2736/CN108274145A.pdf (accessed on 20 July 2021).

60. Ma, C.L.; Xue, S.B.; Wang, B.; Long, W.M.; Zhong, S.J. Effects of Ga and Ce on the microstructure and properties of cadmium-free silver filler metals. Rare Met. Mater. Eng. 2019, 48, 91-96. [WOS: 000457815200013].

61. Ma, C.L.; Xue, S.B.; Wang, B.; Wang, J.X.; Long, W.M. Study on microstructure and properties of BAg17CuZnSn-xCe filler metals. Trans. China Weld. Inst. 2018, 39, 42-46. [CrossRef]

62. Zhengzhou Research Institute of Mechanical Engineering Co., Ltd. Seamed Flux-Cored Silver Welding Wire with Circular Section: China. ZL 201520230532.4, 7 October 2015. Available online: https:/ / patentimages.storage.googleapis.com/bc/1d/2a/a3043328 7643a1/CN204686290U.pdf (accessed on 20 July 2021). 
63. Zhengzhou Research Institute of Mechanical Engineering Co., Ltd. Semiclosed Flux-Cored Silver Welding Rod: China. ZL 201520230543.2, 19 August 2015. Available online: https://patentimages.storage.googleapis.com/b3/49/34/5e9bb5c0569fa9 /CN204565442U.pdf (accessed on 20 July 2021).

64. Zhengzhou Research Institute of Mechanical Engineering Co., Ltd. Seamless Flux-Cored Silver Welding Wire with Non-Circular Cross Section: China. ZL 201520230603.0, 7 October 2015. Available online: https://patentimages.storage.googleapis.com/d7/8 2/2c/41309543c8f20d/CN204686292U.pdf (accessed on 20 July 2021).

65. Zhengzhou Research Institute of Mechanical Engineering Co., Ltd. Flux-Cored Silver Brazing Filler Metal with Alloys for Improving Tougheness: China. ZL 201510269707.7, 25 August 2017. Available online: https:/ / patentimages.storage.googleapis. com/77/09/1f/0a38a7c11bfbd3/CN104907723B.pdf (accessed on 20 July 2021).

66. Lucas-Milhaupt, Inc. Low Silver, Low Nickel Brazing Material: U.S. US 20160032429A1, 4 February 2016. Available online: https:/ / patentimages.storage.googleapis.com/b1/98/a0/8f12ec8b05ddc3/US20160032429A1.pdf (accessed on 20 July 2021).

67. Ma, C.L. Effect of Ga and Ce on the Microstructures and Properties of Ag17CuZnSn Filler Metals. Ph.D. Thesis, Nanjing University of Aeronautics and Astronautics, Nanjing, China, 2017.

68. Lv, D.F.; Chen, B.Y.; Zhong, S.J.; Dong, X.; Huang, J.L. Development and Application of New Environment-Friendly Flux Coated Filler Metal Ring. Weld. Join. 2017, 4, 17-20. [CrossRef]

69. Zhengzhou Research Institute of Mechanical Engineering Co., Ltd. Spring-Like Environment-Friendly Flux-Coated Silver Brazing Filler Ring: China. ZL 201510269713.2, 17 May 2017. Available online: https:/ / patentimages.storage.googleapis.com/1c/67/51/ 16cbb9120df8ac/CN104907724B.pdf (accessed on 20 July 2021).

70. Zhengzhou Research Institute of Mechanical Engineering Co., Ltd. Efficient Flux Coated Brazing Filler Metal with Strong Adhesive Force: China. ZL 201510269610.6, 28 November 2017. Available online: https:/ / patentimages.storage.googleapis.com/ e3/e5/16/d0f029eb130721/CN104907721B.pdf (accessed on 20 July 2021).

71. Lucas-Milhaupt, Inc. Process for Flux Coating Braze Preforms and Discrete Parts: U.S. US 9314862B2, 19 April 2016. Available online: https:/ / patentimages.storage.googleapis.com/5b/f7/ef/cda640aaa55dc3/US9314862.pdf (accessed on 20 July 2021).

72. Zhengzhou Research Institute of Mechanical Engineering Co., Ltd. Flux-Coated Brazing Filler Ring with Anti-Skidding Bumps: China. ZL 201520230547.0, 19 August 2015. Available online: https:/ / patentimages.storage.googleapis.com/6c/28/45/8bd747 ce2a3326/CN204565443U.pdf (accessed on 20 July 2021).

73. Zhengzhou Research Institute of Mechanical Engineering Co., Ltd. Flux-Coated Cu-P-Sn Brazing Filler Ring: China. ZL 201520230580.3, 7 October 2015. Available online: https://patentimages.storage.googleapis.com/c7/63/11/d1407c6c8869f1 /CN204686291U.pdf (accessed on 20 July 2021).

74. Zhengzhou Research Institute of Mechanical Engineering Co., Ltd. Flux-Coated Cu-P-Sn Brazing Filler Ring Instead of Silver and Manufacturing Method Thereof: China. ZL 201510180763.3, 8 March 2017. Available online: https:/ / patentimages.storage. googleapis.com/ec/85/ba/05691064a1707f/CN104759781B.pdf (accessed on 20 July 2021).

75. Sunkwang Brazing Filler Metal Co., Ltd. Flux-Containing Brazing Agent Brazed at Low Temperature: South Korea WO2005123309A1, 29 December 2005. Available online: https://patentimages.storage.googleapis.com/23/c5/f5/c76c1d169a4f7 d/WO2005123309A1.pdf (accessed on 20 July 2021).

76. Yantai Guguang Welding Materials Co., Ltd. Preparation Method for Low-Temperature Copper/Aluminum Filler Metals and the Low-Temperature Copper/Aluminum Filler Metals: China. CN 201410188611.3, 25 November 2015. Available online: https:/ / patentimages.storage.googleapis.com/6b/50/fd/d6160f34a7865b/CN105081601A.pdf (accessed on 20 July 2021).

77. Changzhou Sinleh Metal New Material Co., Ltd. Environment-Friendly Corrosion-Free Flux-Containing Brazing Filler Metal for Brazing Aluminum Alloy and Copper Alloy and Preparation Method Thereof: China. CN 202010459591.4, 8 September 2020. Available online: https:/ / patentimages.storage.googleapis.com/27/ac/88/ac8604232e1624/CN111633355A.pdf (accessed on 20 July 2021).

78. Li, X.P.; Zhu, K.; Yu, X.Q.; Ding, T.R.; Li, Y. Brazing of 3003 aluminum alloy with Al-12Si self-fluxing filler metal ring. Weld. Join. 2014, 1, 54-56.

79. Li, X.P.; Long, W.M.; Chen, X.; Shen, Y.X.; Zhong, S.J. Influence of sintering pressure on property of self-fluxing filler metal. Trans. China Weld. Inst. 2015, 36, 97-100.

80. Li, X.P.; Long, W.M.; Pei, Y.Y.; Huang, J.L. Influence of sintering temperature on properties of self-fluxing filler metal. Weld. Join. 2013, 7, 44-47.

81. Li, X.P.; Long, W.M.; Shen, Y.X.; Pei, Y.Y. Effect of sintering time on microstructure and mechanical properties of self-fluxing filler metal. Trans. China Weld. Inst. 2014, 35, 59-62.

82. He, P.; Lin, P.P. The systematic project involving brazes development and intelligent brazing technology innovation: A materials genome perspective. Mater. Rep. 2019, 33, 156-161. [CrossRef]

83. He, P.; Zhang, L. Development of intelligent brazing technology. Trans. China Weld. Inst. 2017, 38, 124-128. [CrossRef] 